\title{
The evaluation of learning of chemistry in the faculty of Ben M'Sik: Dysfunction and axes for improvement
}

\author{
Soumia TAMANI ${ }^{\mathrm{a}, \mathrm{b}}$, Mohammed TALBI ${ }^{\mathrm{b}}$ et Mohamed RADID ${ }^{\mathrm{a}, \mathrm{b}}$ \\ ${ }^{a,}$ Laboratory of Physical Chemistry of Materials Hassan II-Mohammedia University Faculty of Sciences Ben \\ M'sik Casablanca Morroco \\ ${ }^{b}$ Observatory for Research in Didactics and University Pedagogy (ORDIPU), University Hassan -II- \\ Mohammedia, Casablanca, Morocco.
}

\begin{abstract}
:
At university as at other levels of education, evaluation is an integral part of the daily work of teachers. The objective of this article is to examine the evaluation practices of higher education trainings, in particular to the die SMC at the Faculty of Sciences Ben M'Sik, after ten years of LMD(Licence(BA),Master Degree, Doctorate) system adoption.

The methodology of this study is based on administering a questionnaire to a group of 23 teachers, representing $40 \%$ of the faculty of the Chemistry Department of the FSB who have responded to several items related to these four dimensions: Characteristics of the course, evaluation tools, evaluation practices and teacher / student communication.

A second questionnaire was administered to $20 \%$ of students studying SMC both S4 and S6 levels. It involved three dimensions: branch, teacher / student communication, and evaluation practices.

This study allowed us to detect a dysfunction in the evaluation of learning caused by certain practices that concern:

$>$ The imbalance between the number of students and those of teachers and inadequate educational infrastructure quality does not promote the implementation of formative assessment, mainly oriented on the individual skills of learners.

$>$ The absence of training in general education and technical evaluation of teachers affect negatively the quality of training.

$>$ The assessment practices are not effective:

a) Lack of course objectives;

b) The absence of a framework of quizzes and exams;

c) Low Teacher / student communication;

d) The competences covered by the evaluation are especially understanding, memorization and application.

e) Absence of assessment of prerequisites;

f) Undiversified evaluation tools;

g) Insufficient Students' errors analysis.

Keywords: evaluation of learning, continuous controls, higher education, prerequisites, assessment tools.
\end{abstract}

\section{Introduction}

Several studies have been made in the practical assessment of learning at the university include, we ( Blais et al., 1997) [1], (Grilles, 2011) [2], (Marc ROMAINVILLE, 2002)[3], (Bourema KONATE, Mme TRAORE Kadaouyé DAMBA et Kalilou SIDIBE 2007) [4] et (Said El Melhaoui, 2012) [5].

With the objective to analyze the practices of evaluation of learning in the Faculty of Science Ben M'sik, a investigation was carried out in spring 2013, it was sent to chemistry teachers and students of the SMC die both S4 and S6 levels in what was sent a questionnaire to teachers composed of four dimensions:

- Characteristics of the course;

- Evaluation tools;

- Evaluation practices;

- Teacher / student communication;

Another questionnaire consisting of three dimensions was submitted to the students:

- Branch;

- Teacher/ student communication;

- Evaluation practices. 


\section{II-Study methodology and characteristics of the survey sample}

In the beginning, the study targeted the teachers of the Faculty of Sciences, Ben M'Sik. A survey questionnaire was administered to 23 teachers, a number which makes up $40 \%$ of the teaching chemistry at the FSB.

Next, a questionnaire was administered to 90 students. That number represents $20 \%$ of discipline SMC of the two levels S4 and S6.

III-Result analysis (attached the results recorded)

The research we conducted with teachers and students from the Faculty of Science Ben M'Sik allowed us to raise the following points:

\section{1-Course objectives}

From the interviews with the teachers, it was noted that most teachers confuse the content of the course with its objectives, which is clearly illustrated in the statement of tracks (example: Track: Matter-science Chemistry). There is a confusion between the objectives, information and course content, and also, from students' answers, about the communication of course objectives by their teachers ( $25.6 \%$ of students confirmed this).

This calls into question the teachers' answers about the:

$>$ Definition of course objectives;

Communication of these objectives to students;

$>$ Evaluation of these objectives.

We need to define the objectives of each course, formalize them in the statement of each track, communicate them to all teachers and all students, and guide the evaluation of learning in these objectives.

\section{2-Assessment tools}

Assessment tools used in the Faculty of Science Ben M'sik are not diversified.

So it's necessary to diversify assessment tools:

$>$ Integrate multiple choice, sentence completion, true / false, and short-answer questions to overcome the difficulties of the French language in the student and at the same time facilitate the correction of exams for the teachers (S1 to S6).

$>$ Integrate presentations and oral examinations ( $50 \%$ of the final grade for the S5 and S6) to develop autonomy and communication in the student.

$>$ Integrate problem situations and case studies (S5 and S6)

$>$ To schedule more practical work and evaluate it practically (S1 to S6).

$>$ Organize more outings, field courses and ask questions in real situations, depending on the nature of each subject.

\section{3-The competences covered in the evaluation}

At the Faculty of Science Ben M'Sik:

The competences covered in the evaluation of learning are especially: understanding, memory and application. But the main objective of any educational system is to be based primarily on logic for the sake of training critical thinking and the stimulation of intelligence in order to integrate an information and communication society, and not just depend on storage and memorisation .

Therefore, it is proposed to change the testing system. The conventional tests should be replaced by objective ones that evaluate not only memorizing and understanding but also the ability to analyze, synthesize, solve real problems and make decisions (bloom's taxonomy), besides these skills should be defined for each subject.

\section{4-Absence of a repository of quizzes and exams}

The repository of quizzes and exams aims to:

$>$ Unify vision among teachers of the same subject during the handling of exams and quizzes (several teachers of the same subject for a large number of students).

$>$ Increase the credibility of exams.

$>$ Cover and represent the entire curriculum for efficient drainage of the principle of equal opportunities.

$>$ Find a basis for the evaluation of quizzes and exams.

D Unify reference for all participants in the process for founding exams on a contractual basis between all parties involved.

From the answers of teachers and students of the Faculty of Science Ben Sik, we can say that:

$>$ The vision among teachers in the implementation of quizzes is not always unique.

$>$ There is a poor coverage of the course. 
> The evaluation of quizzes and exams' topics is fairly assessed, and even when there is an assessment, it is not effective in the absence of a basis to be compared.

$>$ The average number of quizzes carried out by subject is one per semester, which is not in accordance with what is prescribed in the specifications. However, the " CNPN Project of the BA Cycle (Fundamental Studies BA and Professional BA) Amending CNPN taken by Order No. 1695-1604 of 24 September 2004" stipulates an elimination of continuous assessment in semesters S1 and S2 due to the high number of students, while there is an evolution in students' grades in quiz 1 ( thermochemistry: $13.50 \%$ who had a score higher than 10 and $48.41 \%$ who had a score of 0$)$ in quiz $2(41.42 \%$ who had a score higher than 10 and $8.31 \%$ who had a score of 0 ).

$>$ The quizzes' and exams' questions are not clearly formulated.

$>$ The marking of the tests is often subjective.

A clear dissimilarity between the students' and teachers' answers is revealed, which is quite normal in the absence of a repository of quizzes and exams.

It is proposed to develop a repository of quizzes and exams, respect it and communicate it to all teachers and students.

This repository must contain for each subject under each semester:

$>$ The number of quizzes.

$>$ The objectives to be evaluated.

$>$ The schedule of quizzes and exams.

$>$ The percentage of each part of the course for each quiz and exam.

$>$ The percentage of each level of difficulty.

$>$ The method of average calculation.

$>$ The skills targeted in a well-defined percentage.

Review the proposed elimination of continuous assessment for S1 and S2 as they proved important while being applied.

\section{5-Teacher / student communication}

At the Faculty of Science Ben M'Sik, there is a wide discrepancy between the answers of teachers and students about the communication of course objectives, prerequisites, evaluation criteria, method of calculation of the average and the schedule of quizzes and exams.

Indeed, the repository of quizzes and exams previously proposed must be communicated to all students, in addition to trying to stabilize the number of students for each teacher (courses, directed work, and practical work) to ensure good communication and proper monitoring of students.

\section{6-Evaluation of prerequisites}

Most chemistry teachers of the Faculty of Science Ben M'sik confirm that the prerequisites which the student must know before the beginning of each class are defined, but they are not well communicated to the students ( $85.4 \%$ of students say that), their assessment is low, and their intervention when they find a lack of a certain prerequisite is likewise low.

In the statement of tracks, the prerequisites are not well formalized. They are rarely defined as courses in general, and from the interview with teachers, we have noticed their ignorance of those of secondary school which creates rupture between high school and university.

By analyzing the national educational standards of the Hassan II Mohammedia University we found:

$>$ Registration requirements in S5 and S6 depend on S1 and S2 semesters validation and at least two modules of S3 and S4;

- For the fall semester, the student must be registered for the invalidated modules of semester S3 and complete his/her registration by the modules of semester S5.

- For the spring session, the student must be registered for invalidated modules in semester S4 and complete his/her registration by semester S6 modules .

To register for S3 and S4 modules:

- For the fall semester, the student must re-register; for invalidated modules in semester S1 and complete the registration by modules of semester S3.

- For the spring session, the student must re-register; for invalidated modules in semester S2 ,and complete the registration by semester S4 modules.

In general the student registers in 4 modules per session.

Therefore, the seasonal distribution of semesters: Fall Session (S1, S3, S5) and the Spring Session (S2, S4, S6) neglects the prerequisites that the student must have, which creates a problem in the student to follow some 
modules (because $\mathrm{s} / \mathrm{he}$ did not validate the module that contains the necessary prerequisites or even in some cases study it.).

We must define the prerequisites of each course, formalize them in the description of each track for each subject, communicate them to all teachers and students, assess them, intervene if there is need, and give a backup semester, especially for students of S1 and S2.

We also suggest duplicating semesters.

\section{7-Formative Evaluation}

Chemistry Teachers of the Faculty of Sciences Ben M'sik correct students' errors in directed work (even if this is not enough) better during the course, which is quite normal considering the high number of students in the course. However, this correction is rarely performed after quizzes, given that many students are aware of the usefulness of continuous assessment.

As a result, students do not receive feedback, views or advice, thereby continuous assessment loses its true value; hence, the need to establish a formative assessment system.

As for the analysis, synthesis, and interpretation of students' grades, teachers should give more attention to these aspects, and not just relegate them only to module and track staff.

From an interview with teachers, it seems that the decisions based on the interpretation of the results do not take into consideration the following points [6]:

Modification of the approach of the course, changing the adopted strategy, repetition of explanation and the organization of educational support sessions for the students who are lagging.

Analysis, synthesis, interpretation of students' grades and decision making according to the previously defined aspects, may be feasible and effective only if we stabilize the mass of students for each teacher (Course, directed work) in order to ensure proper monitoring.

Finally, we suggest a teacher training for all teachers so that a better collaboration can be met.

\section{IV- Conclusion}

The evaluation of learning of chemistry Faculty of Science Ben Sik has more weaknesses than strengths. This is the result which leads the study.

This failure is due to some parameters which are:

This study allowed us to detect a dysfunction in the evaluation of learning caused by certain practices that concern:

$>$ The imbalance between the number of students and those of teachers and inadequate educational infrastructure quality does not promote the implementation of formative assessment, mainly oriented on the individual skills of learners.

$>$ The absence of training in general education and technical evaluation of teachers affect negatively the quality of training.

$>$ The assessment practices are not effective:

a) Lack of course objectives;

b) The absence of a framework of quizzes and exams;

c) Low Teacher / student communication;

d) The competences covered by the evaluation are especially understanding, memorization and application.

e) Absence of assessment of prerequisites;

f) Undiversified evaluation tools;

g) Insufficient Students' errors analysis.

\section{References}

[1] Blais J.G, Laurier M., Van der Maren J.M., Gervais C., Lévesque M., Pelletier G.(1997). L'évaluation des apprentissages à l'université de Montréal et dans ses écoles affiliées. Montréal groupe de Recherche Interdisciplinaire en Pédagogie Universitaire.

[2] Gilles,J.-L, Detroz, P., Blais, J.-G.(2011). An international on line survey of the practices and perceptions of education professors with respect to the assesment of learning in the classroom. Assesment and Evaluation in Higher Education, volume 36, Number 6, pp.719-733.

[3] Marc ROMAINVILLE, l'évaluation des acquis des étudiants dans l'enseignement universitaire (2002).

[4] Pr. Dénis Dougnon, Bourema KONATE, Mme TRAORE Kadaouyé DAMBA et Kalilou SIDIBE, les pratiques d'évaluation des apprentissages à l'université (2007).

[5] Said El Melhaoui, Abdellali Kaaouachi, Brahim Ouafae, les déterminants des pratiques d'évaluation des apprentissages à l'université Mohammed Premier, colloque national L'enseignement supérieur au Maroc : quel enseignement pour quelle efficacité ? Rabat 12 décembre 2012.

[6] Abderrahmane TOUMI ; l'approche par compétences: un nouveau regard sur l'élaboration des curricula et la planification des apprentissages. 
Table 1

\section{ANNEX1}

\begin{tabular}{|l|l|l|l|l|l|}
\hline & Always & Often & Sometimes & Rarely & Never \\
\hline The objectives of the courses are defined & $59,1 \%$ & $31,8 \%$ & $9,1 \%$ & $0 \%$ & $0 \%$ \\
\hline The practical relevance of the topics is demonstrated & $30,4 \%$ & $17,4 \%$ & $34,8 \%$ & $13,0 \%$ & $4,3 \%$ \\
\hline $\begin{array}{l}\text { The articulation of courses with other subjects or } \\
\text { disciplines is evidenced }\end{array}$ & $17,4 \%$ & $30,4 \%$ & $39,1 \%$ & $4,3 \%$ & $8,7 \%$ \\
\hline The conduct of course session is planned & $66,7 \%$ & $23,8 \%$ & $0 \%$ & $4,8 \%$ & $4,8 \%$ \\
\hline
\end{tabular}

Table 2

\begin{tabular}{|l|l|l|l|l|l|}
\hline & Always & Often & Sometimes & Rarely & Never \\
\hline $\begin{array}{l}\text { Vision between the teachers of the subject during } \\
\text { conduct of quizzes and exams is unique }\end{array}$ & $17,4 \%$ & $39,1 \%$ & $13,0 \%$ & $21,7 \%$ & $8,7 \%$ \\
\hline The evaluation covers the entire curriculum & $30,4 \%$ & $26,1 \%$ & $17,4 \%$ & $13,0 \%$ & $13,0 \%$ \\
\hline $\begin{array}{l}\text { The control subjects and examinations are evaluated } \\
\text { after each execution }\end{array}$ & $19,0 \%$ & $23,8 \%$ & $38,1 \%$ & $9,5 \%$ & $9,5 \%$ \\
\hline Evaluation is oriented along the course objectives & $39,1 \%$ & $34,8 \%$ & $17,4 \%$ & $8,7 \%$ & $0 \%$ \\
\hline $\begin{array}{l}\text { After each quiz and exam: You analyse the student } \\
\text { grades. }\end{array}$ & $34,8 \%$ & $43,5 \%$ & $17,4 \%$ & $0 \%$ & $4,3 \%$ \\
\hline $\begin{array}{l}\text { After each quiz and exam: You make a synthesis and } \\
\text { interpretation of the results achieved }\end{array}$ & $27,3 \%$ & $45,5 \%$ & $9,1 \%$ & $4,5 \%$ & $13,6 \%$ \\
\hline $\begin{array}{l}\text { After each quiz and exam: You take a decision } \\
\text { following these results }\end{array}$ & $27,3 \%$ & $27,3 \%$ & $22,7 \%$ & $4,5 \%$ & $18,2 \%$ \\
\hline
\end{tabular}

Table 3

\begin{tabular}{|l|l|l|l|l|l|}
\hline & Always & Often & Sometimes & Rarely & Never \\
\hline The prerequisites that the student must have are defined & $30,4 \%$ & $65,2 \%$ & $87,0 \%$ & $13,0 \%$ & $0 \%$ \\
\hline $\begin{array}{l}\text { You evaluate these prerequisites before starting each } \\
\text { course }\end{array}$ & $13,0 \%$ & $8,7 \%$ & $34,8 \%$ & $13,0 \%$ & $30,4 \%$ \\
\hline You intervene when you discover a lack of a prerequisite & $30,4 \%$ & $39,1 \%$ & $17,4 \%$ & $8,7 \%$ & $4,3 \%$ \\
\hline
\end{tabular}

Table 4

\begin{tabular}{|l|l|l|l|l|l|}
\hline & Always & Often & Sometimes & Rarely & Never \\
\hline The difficulties encountered by students are noted: During the course & $20,0 \%$ & $25 \%$ & $25 \%$ & $10 \%$ & $20 \%$ \\
\hline $\begin{array}{l}\text { The difficulties encountered by students are noted: During directed } \\
\text { work }\end{array}$ & $39,1 \%$ & $52,2 \%$ & $4,3 \%$ & $0 \%$ & $4,3 \%$ \\
\hline The difficulties encountered by students are noted : After each quiz & $39,1 \%$ & $39,1 \%$ & $8,7 \%$ & $4,3 \%$ & $8,7 \%$ \\
\hline The difficulties encountered by students are noted : After each exam & $38,1 \%$ & $28,6 \%$ & $19,0 \%$ & $0 \%$ & $14,3 \%$ \\
\hline The difficulties encountered by the students are analyzed & $17,4 \%$ & $21,7 \%$ & $39,1 \%$ & $8,7 \%$ & $13,0 \%$ \\
\hline You put corrective actions to overcome these problems in the students & $13,6 \%$ & $40,9 \%$ & $31,8 \%$ & $9,1 \%$ & $4,5 \%$ \\
\hline $\begin{array}{l}\text { You put preventive actions to overcome these problems in the } \\
\text { students }\end{array}$ & $18,2 \%$ & $50,0 \%$ & $13,6 \%$ & $9,1 \%$ & $9,1 \%$ \\
\hline
\end{tabular}

Table 5

\begin{tabular}{|l|l|l|l|l|l|}
\hline & Always & Often & Sometimes & Rarely & Never \\
\hline Quizzes and exams evaluate: Knowledge & $52,2 \%$ & $30,4 \%$ & $4,3 \%$ & $8,7 \%$ & $4,3 \%$ \\
\hline Quizzes and exams evaluate: Understanding & $60,9 \%$ & $30,4 \%$ & $4,3 \%$ & $0 \%$ & $4,3 \%$ \\
\hline Quizzes and exams evaluate : Application & $39,1 \%$ & $30,4 \%$ & $26,1 \%$ & $0 \%$ & $4,3 \%$ \\
\hline Quizzes and exams evaluate: The capacity to analyze & $21,7 \%$ & $26,1 \%$ & $43,5 \%$ & $4,3 \%$ & $4,3 \%$ \\
\hline Quizzes and exams evaluate: The capacity for synthesis & $13,0 \%$ & $17,4 \%$ & $52,2 \%$ & $4,3 \%$ & $13,0 \%$ \\
\hline Quizzes and exams evaluate : The capacity of real-problem solving & $13,0 \%$ & $17,4 \%$ & $34,8 \%$ & $17,4 \%$ & $17,4 \%$ \\
\hline Quizzes and exams evaluate :Decision taking & $4,3 \%$ & $13,0 \%$ & $43,5 \%$ & $13,0 \%$ & $26,1 \%$ \\
\hline
\end{tabular}


The evaluation of learning of chemistry in the faculty of Ben M'Sik: Dysfunction and axes for

Table6

\begin{tabular}{|l|l|l|l|l|l|}
\hline & Always & Often & Sometimes & Rarely & Never \\
\hline Closed tools: MCQ (Multiple Choice Questions) & $0 \%$ & $9,1 \%$ & $18,2 \%$ & $22,7 \%$ & $50,0 \%$ \\
\hline Closed tools OQSA (open questions and short answers) & $9,1 \%$ & $18,2 \%$ & $22,7 \%$ & $13,6 \%$ & $36,4 \%$ \\
\hline Closed Tools: The type questions in sentence completion & $59,1 \%$ & $13,6 \%$ & $13,6 \%$ & $13,6 \%$ & $59,1 \%$ \\
\hline Open tools: Exercises & $59,1 \%$ & $36,4 \%$ & $4,5 \%$ & $0 \%$ & $0 \%$ \\
\hline Open tools: Situational Problem & $9,1 \%$ & $31,8 \%$ & $27,3 \%$ & $13,6 \%$ & $18,20 \%$ \\
\hline Open tools: Case Study & $0 \%$ & $30,4 \%$ & $21,7 \%$ & $17,4 \%$ & $30,4 \%$ \\
\hline An Oral Examination / Presentation & $17,4 \%$ & $26,1 \%$ & $21,7 \%$ & $4,31 \%$ & $30,4 \%$ \\
\hline A Practical Exam & $13,0 \%$ & $21,7 \%$ & $17,4 \%$ & $26,1 \%$ & $21,7 \%$ \\
\hline
\end{tabular}

Table 7

\begin{tabular}{|l|l|l|l|l|l|}
\hline & Always & Often & Sometimes & Rarely & Never \\
\hline MCQ & $0 \%$ & $9,1 \%$ & $18,2 \%$ & $22,7 \%$ & $50,0 \%$ \\
\hline OQSA & $9,1 \%$ & $18,2 \%$ & $22,7 \%$ & $13,6 \%$ & $36,4 \%$ \\
\hline $\begin{array}{l}\text { Questions } \\
\text { In complete sentence }\end{array}$ & $59,1 \%$ & $13,6 \%$ & $13,6 \%$ & $13,6 \%$ & $59,1 \%$ \\
\hline Exercices & $59,1 \%$ & $36,4 \%$ & $4,5 \%$ & $0 \%$ & $0 \%$ \\
\hline Situational Problem & $9,1 \%$ & $31,8 \%$ & $27,3 \%$ & $13,6 \%$ & $18,20 \%$ \\
\hline Case Study & $0 \%$ & $30,4 \%$ & $21,7 \%$ & $17,4 \%$ & $30,4 \%$ \\
\hline Oral Examination / Presentation & $17,4 \%$ & $26,1 \%$ & $21,7 \%$ & $4,31 \%$ & $30,4 \%$ \\
\hline Practical Exam & $13,0 \%$ & $21,7 \%$ & $17,4 \%$ & $26,1 \%$ & $21,7 \%$ \\
\hline
\end{tabular}

Table 8

\begin{tabular}{|l|l|l|l|l|l|}
\hline & Always & Often & Sometimes & Rarely & Never \\
\hline Students are informed with the evaluation criteria. & $22,7 \%$ & $40,9 \%$ & $22,7 \%$ & $4,5 \%$ & $9,1 \%$ \\
\hline $\begin{array}{l}\text { Students are informed with the method of calculating the } \\
\text { average. }\end{array}$ & $40,9 \%$ & $31,8 \%$ & $22,7 \%$ & $4,5 \%$ & $0 \%$ \\
\hline Quizzes and exams are conducted according to a set schedule. & $47,8 \%$ & $21,7 \%$ & $17,4 \%$ & $13,0 \%$ & $0 \%$ \\
\hline The schedule is communicated to students. & $47,87 \%$ & $21,7 \%$ & $21,7 \%$ & $4,3 \%$ & $4,3 \%$ \\
\hline The prerequisites are communicated to students & $13,0 \%$ & $26,1 \%$ & $30,4 \%$ & $8,7 \%$ & $21,7 \%$ \\
\hline The course objectives are communicated to students & $39,1 \%$ & $43,5 \%$ & $0 \%$ & $13,0 \%$ & $4,3 \%$ \\
\hline
\end{tabular}

Table9

\section{ANNEXE 2}

\begin{tabular}{|c|c|c|c|c|c|}
\hline & Always & Often & Sometimes & Rarely & Never \\
\hline Your teachers communicate to you the objectives of the course & $7,0 \%$ & $11,6 \%$ & $37,2 \%$ & $27,9 \%$ & $16,3 \%$ \\
\hline You are informed with the schedule of quizzes and exams & $3,4 \%$ & $4,5 \%$ & $9,0 \%$ & $12,4 \%$ & $70,8 \%$ \\
\hline You are aware of the criteria for evaluating quizzes and exams? & $2,2 \%$ & $3,3 \%$ & $28,9 \%$ & $21,1 \%$ & $44,4 \%$ \\
\hline $\begin{array}{l}\text { The teachers communicate to you the prerequisites that you need to } \\
\text { know before the start of each course }\end{array}$ & $6,7 \%$ & $7,9 \%$ & $57,3 \%$ & $22,5 \%$ & $5,6 \%$ \\
\hline You are informed with the method of calculating the average & $0 \%$ & $4,4 \%$ & $7,8 \%$ & $12,2 \%$ & $75,6 \%$ \\
\hline Teachers notify you with other students' mistakes & $4,4 \%$ & $10,0 \%$ & $42,2 \%$ & $32,2 \%$ & $11,1 \%$ \\
\hline
\end{tabular}

Table10

\begin{tabular}{|l|c|c|c|c|c|}
\hline & Always & Often & Sometimes & Rarely & Never \\
\hline Teachers assess the prerequisites before you begin each course. & $2,2 \%$ & $11,2 \%$ & $29,2, \%$ & $24,7 \%$ & $32,6 \%$ \\
\hline $\begin{array}{l}\text { Teachers intervene when they find a lack of a certain } \\
\text { prerequisite. }\end{array}$ & $5,6 \%$ & $4,4 \%$ & $14,4 \%$ & $31,1 \%$ & $44,4 \%$ \\
\hline Teachers correct students' errors: In the course & $6,7 \%$ & $12,4 \%$ & $25,8 \%$ & $30,3 \%$ & $24,7 \%$ \\
\hline Teachers correct students' errors: In directed work & $19,1 \%$ & $15,7 \%$ & $41,6 \%$ & $14,6 \%$ & $9,0 \%$ \\
\hline Teachers correct students' errors: After each quiz & $3,4 \%$ & $5,7 \%$ & $11,5 \%$ & $18,4 \%$ & $60,9 \%$ \\
\hline Are the exam questions clearly stated? & $3,3 \%$ & $16,7 \%$ & $43,3 \%$ & $30,0 \%$ & $6,7 \%$ \\
\hline Does the review cover all the chapters studied in the course? & $11,1 \%$ & $30,0 \%$ & $34,4 \%$ & $20,0 \%$ & $4,4 \%$ \\
\hline
\end{tabular}


The evaluation of learning of chemistry in the faculty of Ben M'Sik: Dysfunction and axes for

\begin{tabular}{|c|c|c|}
\hline Items & \multicolumn{2}{|l|}{ Percent } \\
\hline \multicolumn{3}{|l|}{ How many quizzes do you have in each subject? } \\
\hline 0 & \multicolumn{2}{|c|}{1,1} \\
\hline 1 & \multicolumn{2}{|c|}{51,1} \\
\hline 2 & \multicolumn{2}{|c|}{46,7} \\
\hline 3 & \multicolumn{2}{|c|}{1,1} \\
\hline \multicolumn{3}{|l|}{ Is there consistency between the content studied and the quizzes' topics? } \\
\hline Yes & \multicolumn{2}{|c|}{21,3} \\
\hline Rather yes & \multicolumn{2}{|c|}{40,4} \\
\hline Rather not & \multicolumn{2}{|c|}{21,3} \\
\hline No & \multicolumn{2}{|c|}{16,9} \\
\hline \multicolumn{3}{|l|}{ The distribution of quizzes for each subject in each semester is } \\
\hline Good & \multicolumn{2}{|c|}{12,4} \\
\hline Average & \multicolumn{2}{|c|}{65,2} \\
\hline $\mathrm{Bad}$ & \multicolumn{2}{|c|}{22,5} \\
\hline \multicolumn{3}{|l|}{ How do you estimate this number of quizzes? } \\
\hline High & \multicolumn{2}{|c|}{11,5} \\
\hline Good enough & \multicolumn{2}{|c|}{55,2} \\
\hline Low & \multicolumn{2}{|c|}{33,3} \\
\hline \multicolumn{3}{|l|}{ How does test-making seem to you? } \\
\hline Very objective & \multicolumn{2}{|c|}{3,3} \\
\hline Objective & \multicolumn{2}{|c|}{16,7} \\
\hline Subjective & \multicolumn{2}{|c|}{34,4} \\
\hline Very subjective & \multicolumn{2}{|c|}{45,6} \\
\hline \multicolumn{3}{|l|}{ The planned capacities evaluation } \\
\hline Memory & \multicolumn{2}{|c|}{41,1} \\
\hline Understanding & \multicolumn{2}{|c|}{35,6} \\
\hline Application & \multicolumn{2}{|c|}{11,1} \\
\hline Analysis & \multicolumn{2}{|c|}{8,9} \\
\hline Synthesis & \multicolumn{2}{|c|}{2,2} \\
\hline Creation & & \\
\hline & True & False \\
\hline $\begin{array}{l}\text { According to you: Continuous assessment allows students to get caught up in } \\
\text { time }\end{array}$ & $42 \%$ & $58 \%$ \\
\hline $\begin{array}{l}\text { According to you: Continuous assessment allows the student to reorient if } \\
\text { necessary }\end{array}$ & $26,1 \%$ & $73,9 \%$ \\
\hline $\begin{array}{l}\text { According to you: Continuous assessment allows the teacher to improve his/her } \\
\text { course }\end{array}$ & $48,3 \%$ & $51,7 \%$ \\
\hline
\end{tabular}

